\title{
Soil mineralogy in various land forms of Thotapalli irrigaton project ayacut in North-Coastal Andhra Pradesh
}

K. Himabindu and P. Gurumurthy

Received : 10.09.2018; Revised : 01.11.2018; Accepted : 09.11.2018

MEMBERS OF RESEARCH FORUM:

Corresponding author : P. Gurumurthy, Department of Soil Science and Agricultural Chemistry, Agricultural College, Naira, Srikakulam (A.P.) India Email: peddintigurumurthy@ gmail.com

Co-authors :

K. Himabindu, Department of Soil Science and Agricultural Chemistry, Agricultural College, Naira, Srikakulam (A.P.) India

\section{Summary}

A reconnaissance soil survey was conducted in the ayacut area of Thotapalli major irrigation canal during April to June, 2018 using toposheets of 1: 50,000 scale to study soil characters and mineralogy. Auger bores, mini pits, road cuts of 15 profiles located on uplands and plains were studied. Six representative soil profiles found to cover the major soil types of the study area. The criteria used for study of mineralogy was, soil morphometric characters viz., drainage characters, surface cracks, slicken sides, argillans and chemical characters like soil pH, CEC/ clay, base saturation, $\mathrm{SiO}_{2}, \mathrm{R}_{2} \mathrm{O}_{3}$ as indicators of nature of soil minerals were studied. Soil material from second horizon of each profile was used for powder X-ray diffraction (XRD) analysis. The soils of profiles 1, 3 and 5 were sandy loam to clay loam texture, moderately drained, neutral soil $\mathrm{pH}$, medium CEC/clay ratio and base saturation was more than 35 per cent. The soils of profile 2 were course textures, well drained, moderately acidic, low base status and low CEC/ Clay ratio, relatively high silica $\left(\mathrm{SiO}_{2}\right)$ and low sesquioxides $\left(\mathrm{R}_{2} \mathrm{O}_{3}\right)$ content and prominent quartz and kaolinite peaks in XRD graphs. The soils of 4 and 6 profiles were fine textured, poorly drained, slight to moderately alkaline, high CEC/clay ratio and high base saturation, relatively high silica $\left(\mathrm{SiO}_{2}\right)$ and low sesquioxide $\left(\mathrm{R}_{2} \mathrm{O}_{3}\right)$ contents and prominent XRD peaks of quartz and montomorrilonite. Soils of profile 4 and 6 also found with deep, wide surface cracks during summer and intersecting slicken sides and wedge shaped aggregates found in subsurface horizons. The sand and silt mineralogy was quartzitic in nature. The soil characters, XRD graphs reveled that in uplands and middle land soil profiles was either kaolinite dominant (profile 2) or mixed type clay mineralogy (profiles 1,3 and 5) was observed due to well drainage and relatively course textures, acidic to neutral soil $\mathrm{pH}$ and, while in plains to low land soil profiles (profiles 4 and 6) the mineralogy found was quartz and montmorrilonite due to poor internal drainage condition, fine texture, alkaline soil $\mathrm{pH}$, high base saturation and presence calcarious parent material.

Key words : Soil minerals, Cation exchange capacity, Clay, X-ray diffraction

How to cite this article : Himabindu, K. and Gurumurthy, P. (2018). Soil mineralogy in various land forms of Thotapalli irrigaton project ayacut in North-Coastal Andhra Pradesh. Asian J. Soil Sci., 13 (2) : 87-94 : DOI : 10.15740/HAS/AJSS/13.2/87-94. 